\title{
Social Comparison as a Motivational Agent among Students
}

\author{
Aharon Yadin
}

\begin{abstract}
This paper describes an experimental study that was performed among undergraduate students in their third year out of four required for their Software Engineering degree. The study's main purpose that stems from Maslow's motivational theory (self-actualization), was to explore possible motivational increase through self-grades comparisons. For that reason, a small Excel tool was provided with relative performance comparison graphs. Each student could enter his or her ID number and receive a two graphs figure. One graph represents the average class grades for all assignments and the second graph represents his or her assignments' grades. All assignments were individualized and personalized, so every student got a different set of assignments. The study revealed that the mechanism employed had a positive effect by increasing the average grades. The students' reflection supported these findings as some students expressed their views regarding the importance of their relative performance. The paper concludes with a discussion on the results and future follow-up directions.
\end{abstract}

Index Terms - Enhancing students' motivation, personal and individual assignments, students' learning accountability.

\section{INTRODUCTION}

This paper describes an experimental study aimed at increasing the motivation of students learning towards their Software Engineering degree. 56 students in their third year (out of 4 years required for completing the degree) participated in the study that was conducted as part of the Methods in Software Engineering course. The course's grading scheme is based on 4 home assignments and an exam. All assignments were uniquely individualized due to the lecturer previous good experience with this tactic. Personal and individual assignments [1] imply that each student receives a different assignment so sharing or "borrowing" the solution or parts of the solution is impossible. As was demonstrated already this tactic has a positive influence on the students' learning habits [1], [2]. This study however, moved forward one additional step trying to increase the students' motivation even further. The idea used is based on Maslow's motivational theory [3] and it was implemented as a tool that provided each student with a comparative analysis of his or her relative performance as compared to the class average. This tool provided objective feedback the served the students in evaluating their personal performance in comparison to their peers. The experiment revealed that the comparative method had a positive effect on the learning habits which was manifested in the students' grades. The

Manuscript received March 15, 2014; revised June 2, 2014.

Aharon Yadin is with the Max Stern Yezreel Valley College (YVC), Yezreel Valley, 19300, Israel (e-mail: aharony@yvc.ac.il). paper starts by briefly addressing some of the motivational theories, defines the special traits of the current students' generation and describes the experiment that was performed as part of the study. The last chapter is dedicated to a discussion related to the results obtained and thoughts about possible next stages.

\section{LITERATURE REVIEW}

The term motivation has been addressed by many scholars since the early days of psychology. Motivation stems from the word motion and it is used to define motives for a specific behavior and the motivation theories were developed in order to explain the human behavior. Over the years there were many attempts to explain the motivational drives, attempts that represented the researchers' different views. Maslow's Hierarchy of Needs [3] defined motivation as a set of internal needs. These are hierarchal need and only after one lower need is fulfilled the person is ready to achieve the next level. Nevertheless according to the Hierarchy of needs theory every person is capable and possesses the need to move to the next level of the hierarchy up to the self- actualization which is the highest level. The Self Determination Theory suggested by [4] is rooted in the belief that each human being possesses a need to develop and materialize his or her potential. This theory is based on three fundamental needs: 1 ) autonomy that suggests that the human being needs to feel that the behavior was not imposed on him or her; 2) competence represents a human need that he or she is capable to achieve goals even difficult ones; 3 ) relatedness is the need to love and be loved or being part of the community. The Self Efficacy theory that originated from a social cognitive theory by [5], [6] represents the belief that one has the ability to achieve the goal and complete the task at hand. A similar theory (Nicholls' achievement goal theory [7]) is based on the assumption that every individual has a need to demonstrate his or her ability to succeed and show his or her competence.

\section{A. Generational Differences}

Generational research first appeared in scientific papers over half a century ago and was originally attributed to [8] who analyzed the impact of generational experience on people. In the last 6 decades since then, the generational cohort has been developed further and is used to define a group of people who were born within the same time period. Such a group experiences similar events that shape its attitude and traits [9]. Ref. [10] analyzed similarities and differences between generations spanning over 550 years According to their findings one cycle of history spans about 80 years and is divided into four generational cohorts. The 
last three generations in the twentieth century are:

The Baby Boomers generation, represents the people who were born between 1946 and 1964. The term was used to define the "boom" in the birth rate in the post second world war era. This generation was affected by events such as the Vietnam War, human rights movements, rock and roll music, the arrival of television and the economic prosperity. This generation is considered idealistic and optimistic and highly competitive [11], [12].

Generation X represents people who were born between 1964 and 1980. This generation was affected by new media channels beyond TV including for example games, VCR, FAX machines and the personal computer. This generation saw the fall of the Berlin Wall and end of the Cold War. People in this generation are considered skeptical and independent, relying on their individual abilities rather than institutional help [12].

Generation Y (also referred to as Gen Y, Millennial, or The Digital Generation) represents people who were born between 1981 and 2000. People belonging to this generation were influenced by the rapid expansion of technology and media, and unprecedented immigration growth [12]. The Millennials are the most technological savvy generational group, feeling confident and natural in using a variety of technologies. Generation Y people use the Internet extensively for finding solutions to their problems and expect to be in touch constantly with friends and peers using SMS, instant messaging, chat, and social networks. If consistent with their referent research, they depend on their social network in finding answer to problems. They even tend to prefer Internet networking over the telephone based voice communication [13] and are usually confident in sharing their lives with their virtual friends.

\section{B. Generational College Students}

The vast majority of current college students are Millennials [14]-[16], characterized by the digital technology that surrounds them. As stated by [17] "as long as they [have] been alive, the world has been a connected place, and more than any preceding generation, they have seized on the potential of networked media". Millennials, who are innovative in using technology, seek instant gratification, and value education, but, at times, are (too) confident and unaware of their own lack of skills required for success [18]. Millennials represent a special challenge for the traditional learning system. Students of the 21st century have taught themselves how to network and find the relevant solutions via their networks. They are capable of responding rapidly to multiple stimuli initiated by the changing digital surrounding and expect the learning environment to provide the same challenging and interesting experiences. As [19] suggests, before they leave college, the average Generation Y student (in order of magnitude) has spent approximately:

"over 10,000 hours playing videogames, [has sent and received] over 200,000 emails and instant messages ... [has spent] over 10,000 hours talking on digital cell phones; over 20,000 hours watching TV (a high percentage fast speed MTV) ... And, maybe, at the very most, 5,000 hours of book reading".

There is no surprise that these students are looking for 24/7 study environments to accommodate their learning preferences, instead of using the library [20]. For Millennials, life is an ongoing interactive experience with many activities occurring simultaneously. This multitasking behavior, characterized by fast switching from one activity to the other, dominates these students' attention span. Living in a fast-moving world (fast food, Internet banking, online shopping), Millennials have zero tolerance for delays [21] and expect the information, responses or resources to be available immediately, when and where needed [22]. Many Generation Y students balance their life studies and social life with full- or part- time work [23].

\section{THE STUDY}

The current study was initiated in order to try and cope better with the Millennials different traits that affect their learning. As observed by many researchers, Millennials are competitive and sometimes obsessed with their grades however it is not directly linked to their learning [24]. In most cases these are self-centered individuals who have a positive attitude but poor learning habits [25]. Their high ambition to succeed combined with their advanced technology understanding and the era of "share everything" leads them sometimes to cheat on their assignments. Ref. [2], [24], [26] Taking into consideration all these factors, the study that was conducted as an experiment raised a simple research question. Will it be possible to use the "Share everything" phenomenon for enhancing class competition and thus increasing students' motivation?

The study was performed as part of the "Methods in Software Engineering" course. This is a third year mandatory course that provides understanding about software development methodologies and tools. Most students regard it as an important subject with significant direct bond to their future vocation. The course's structure is based on lectures, 4 tri-weekly assignments and a final exam. Being aware to the students traits (as observed by many researchers) all assignments were uniquely individualized. This means that each student received a different assignment from his/her peers. This was done in order to minimize the possibility of sharing some or all of the assignment. This personal and unique assignments tactic [1] has been used in previous studies and was found to be effective especially for the current students' generation.

\section{A. Methodology}

For sharing the information between the students a small Excel worksheet was developed. The worksheet that included all the assignments' grades was locked. Each student could enter his/her ID number and get a visual graph of his/her grades compared to the class average. As the course proceeded more data was accumulated providing the students with more relevant information on their relative performance. If the tool was used after the first assignment, only the first grade was displayed, however when using the tool after the fourth assignment the graph provides the information that relates to the four assignments (Fig. 1).

Fig. 1 depicts a real example (ID removed) of the grades obtained by a student on the four assignments compared to 
the class average. In this specific case on the first two assignments the student's grades were higher than the class average while for the last two the grade was lower. For the highly motivated students, the tool provided a zoom-in feature that allowed each student to get more elaborated feedback. This feature provided feedback only for one assignment at a time but it was on a per question basis (Fig. 2).

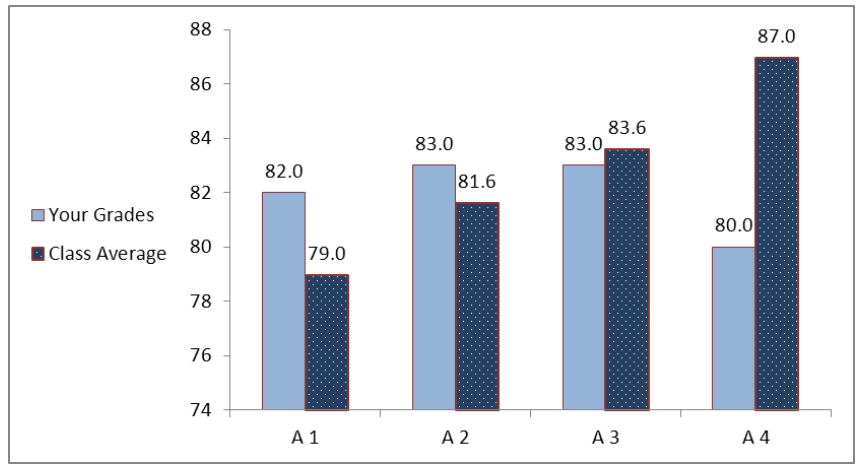

Fig. 1. Assignments' grades comparative graph.

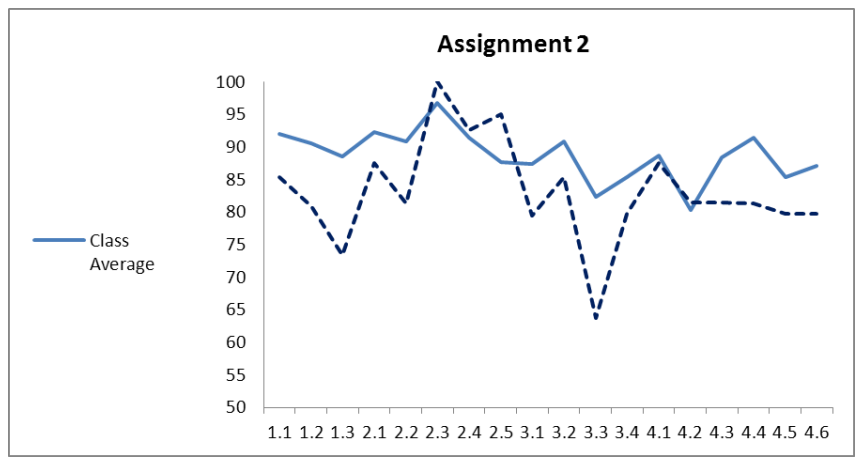

Fig. 2. Elaborated comparative grades' graph.

Fig. 2 depicts an example of an elaborated graph. It relates to the second assignment that included 4 questions' each one divided into additional sub-questions. The student gets an elaborated view in which s/he can compare his or her performance to the class average on each single question resolution. In this specific case the student's performance is worse than the class average (only on assignments 2.2, 2.3 and 2.4 the student's grades were higher than the class average, while for all other assignments the student's grades were lower).

The 56 student of the Software Engineering department that participated in the course were randomly divided into two groups. One group was given access to the tool and was exposed to the class average grades, while the second group that acted as a control group did not get the tool. The methodology used for assessing the tool and its effectiveness was by measuring the trends of the class grades averages as it changed over the course of the semester and especially check the differences between the two groups.

\section{RESUlTS AND DisCUSSION}

After collecting all the data about the assignment' grades it was discovered that while the average grades in the control group fluctuations were minimal (one point), the assignments' grades in the comparative group increased by 9 points (Fig. 3).

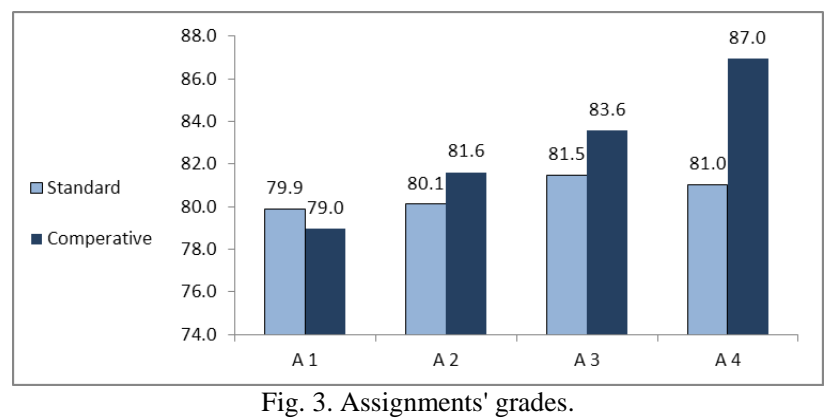

Fig. 3 depicts the average grades of the four assignments in the Standard (control) group and in the comparative (under test) group. While the average grads of the first assignment in both groups were very close (79.9 in the standard group compared to 79.0 in the comparative group), at the end of the semester this difference increased to 6 points. The results obtained are in line with previous findings regarding Millennials. As some researchers have observed, Millennials are competitive and the fact that the comparative group students had the opportunity to compare their performance to the group proved to be a motivational factor. This motivation is even strengthen by the use of the personal and individual assignments that assure that the grades obtained are the result of the students' own work with no parts that were borrowed from others [24]. Another issue that was observed to be beneficial for enhancing motivation for Millennials is feedback [27]. The study supports this finding and in this specific case the feedback was provided in two ways. Each assignment was checked and graded by the instructor' that provided written feedback. The interested students (in the test group) could get a second level of feedback by comparing their performance to the class average. These students (in the test group) could even zoom into their specific answers and check their performance on a per answer basis. This experiment supports other finding by many researchers that claim that special teaching methods are required for the Millennials [27]. The fact that they are multitasked and interested in a variety of subject in parallel to their studies affects their performance. The unique assignments on one hand, that require full personal involvement and the comparative tool that fueled competition proved to be a successful tactic.

These results were clear even from the students' reflections about the course and its structure. Many students in the test group commented on the positive effects of the tool and the fact it provided them the most needed comparison on "How am I doing?" Some said that by using the tool a more competitive but positive class environment as created. On the other hand, some students in the control group were complaining that the experiment was not fair for them. While their peers [in the test group] could enjoy the benefits of the tool it was not available for them. It should be noted, however, that some students said that they were not interested in the tool and never used it. Following these reflections the course web site was analyzed in order to check the number of times the tool was used. It was found that 2 out of the 28 students in the test group never used it. On the other hand there were students who used the tool more than 15 times. For privacy reasons the file cannot be saved on the local PC but even so, it is not clear why someone will want to use the tool so many 
times. May be some students know their peers ID number and wanted to check how they were doing on the assignment. Nevertheless, as can be understood, in every generation including among the Millennials, there exists some degree of diversity and not all students are alike. The fact that the majority of the students used the tool and found it beneficial is sufficient.

\section{FUTURE STUdIES}

This study is a part of a series of studies aimed at finding the proper and optimal tactics to teach the current generation of students. Although this experiment was successful and the suggested tactic proved beneficial, additional similar studies are needed to substantiate the results.

\section{REFERENCES}

[1] A. Yadin and R. Or-Bach, "Fostering individual learning: when and how," SIGCSE Bulletin, vol. 40, no. 4, pp. 83-88, 2008.

[2] A. Yadin, "Millennials and Privacy in the Information Age: Can They Coexist?" IEEE Technol. Soc. Mag., vol. 31, no. 4, pp. 32-38, 2012

[3] A. Maslow, Motivation and Personality, New York: Harper, p. 236, 1054.

[4] E. L. Deci, R. J. Vallerand, L. G. Pelletier, and R. M. Ryan, "Motivation and Education: The Self-Determination Perspective," Educational Psychologist, vol. 26, pp. 325-346, 1991.

[5] A. Bandura, "Self-efficacy: Toward a unifying theory of behavior change," Psychological Review, 1977, vol. 84, pp. 191-215.

[6] D. H. Schunk, "Self-efficacy and academic motivation," Educational Psychologist, vol. 26, pp. 207-231, 1991.

[7] J. G. Nicholls, The Competitive Ethos and Democratic Education, Cambridge, MA: Harvard University Press, 1989.

[8] K. Mannheim, Essays on the Sociology of Knowledge, London: Routledge \& Kegan Paul Ltd., 1952.

[9] V. Jones, J. Jo, and M. Ph, "Future schools and how technology can be used to support millennial and generation-z students," in Proc. 1st International Conference of Ubiquitous Information Technology, Dubai, February 12-14, 2007, pp. 886-891.

[10] W. Strauss and N. H. Generations, The History of America's Future, 1584 to 2069, New York, NY: William Morrow, 1991.

[11] L. C. Lancaster and D. Stillman, When Generations Collide Who They Are. Why They Clash. How to Solve the Generational Puzzle at Work, New York, NY: Harper Business, 2002.

[12] Reesor, L. and K. Schlabach, "Managing Multi-Generations: Strategies for Crossing the Generational Divide in the Workplace," NASPA Leadership Exchange, vol. 4, no. 3, pp. 16-19, 2006.

[13] D. G. Oblinger, "Boomers, Gen-Xers \& Millennials: Understanding the New Students," EduCAUSE Review, vol. 38, no. 4, pp. 37-47, 2003.
[14] N. Howe and W. Strauss, Millennials Rising: The Next Great Generation, New York, NY: Vintage Books, 2000.

[15] D. G. Oblinger and J. L. Oblinger. (2004). Educating the Net Generation. Boulder, CO: EDUCAUSE. [Online]. Available: http://www.educause.edu/educatingthenetgen

[16] J. M. Twenge, Generation Me: Why Today's Young Americans are More Confident, Assertive, Entitled- and More Miserable- than ever Before, New York, NY: Free Press, 2006

[17] S. Crittenden, "Silicon daydreams: Digital pastimes of the wired generation," vol. 6, no. 2, 2002.

[18] L. C. Lancaster, "When generations collide: how to solve the generational puzzle at work," Management Forum Series, March 17, 2004, Synopsis by Rod Cox., 2004

[19] M. Prensky, "Digital natives, digital immigrants, part ii: do they really think differently?" On the Horizon, vol. 9, no. 6, pp. 15-24, 2001

[20] S. Gardner and S. Eng, "What Students want: Generation Y and the changing function of the Academic Library," Portal Libraries and the Academy, vol. 5, no. 3, pp. 405-420, 2005.

[21] J. L. Frand, "The Information age mindset: changes in students and implications for higher education," Educause Review, vol. 35, no. 5, pp. $15-24,2000$.

[22] T. L. Carver and T. L. Cockburn, "Making law more accessible: designing collaborative learning environments for physically remote generation y students," presented at Conference: Learning on the Move, September 26, 2006, Brisbane, Australia.

[23] K. Manuel, "Teaching Information Literacy to Generation y," Journal of Library Administration, vol. 36, no. 1-2, pp. 195-217, 2002.

[24] P. Kandlbinder, "How to teach Gen-Y undergraduates," HERDSA News, vol. 32, no. 2, pp. 28-31, 2010.

[25] M. Bauerlein, The dumbest generation, New York: Jeremy. P. Tacherer/Penguin, 2008.

[26] M. D. Coomes and R. DeBard, Serving the Millennial Generation, San Francisco: Jossey Bass, 2004.

[27] S. Eisner, "Teaching generation Y college students-three initiatives," Journal of College Teaching and Learning, vol. 1, no. 9, pp. 69-84, 2004.

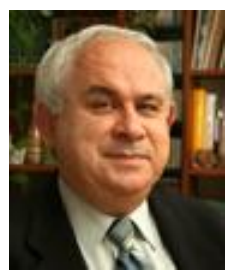

Aharon Yadin is a senior lecturer at the Yezree Valley College (YVC), Management Information Systems Department. Aharon's primary teaching areas are computer architectures and programming and business/management information systems. Prior to entering the academic world, Aharon worked in the High Tech industry. He has over 30 years of IT experience including: management, system performance analysis and enhancement, computer center and IS management, wireless networks and communication technologies and document management.

Aharon has published over one hundred papers, assays and scientific and technological reports (many in Hebrew), he is the author of 10 instructional books and consults the European Commission on software related projects and technologies. 